\title{
DE MARCO TULIO CICERÓN A MANUEL ANTONIO CARREÑO: UN ESTUDIO SOBRE LOS IDEALES DE VIDA DE LAS ÉLITES EN TRES MOMENTOS DE LA HISTORIA
}

\author{
FROM MARCUS TULLIUS CICERO TO MANUEL ANTONIO \\ CARREÑO: A STUDY ON THE LIFE IDEALS OF THE ELITES \\ IN THREE MOMENTS OF HISTORY
}

\section{RAQUEL SOAJE*}

\section{RESUMEN}

El presente artículo se propone rastrear las huellas del De Oficiis o Tratado de los deberes de Marco Tulio Cicerón en ciertos momentos claves de la historia, en que los protagonistas del momento concibieron un arquetipo de hombre, con un ideal de vida acorde a dicho arquetipo y lo plasmaron en una determinada forma de comportamiento social. Se seleccionaron para este fin dos obras modernas que se han preocupado por las buenas maneras o buenas costumbres, como son: De Civilitate Morum Puerilium de Erasmo de Rotterdam y Las cartas de Lord Chesterfield a su hijo, escritas en el siglo XVIII. El trabajo se concentra finalmente en el Manual de urbanidad y buenas maneras del venezolano Manuel Antonio Carreño, que fuera expresión del ideal de vida de las élites de las jóvenes naciones hispanoamericanas, con el fin de realizar un contraste con el tratado ciceroniano.

Palabras clave: Arquetipo, urbanidad, élites, buenas maneras, comportamiento social.

\section{ABSTRACT}

The present article proposes to search for traces of De Oficiis or Teatry of Duties of Marco Tulio Cicero in certain key moments of History. It emphasizes the moment in which the protagonists conceived an archetype of man that had an ideal of life, according to this archetype, which was shaped by a determined way of social behavior. For this aim two modern books that deal with good manners and good customs were selected. These books were Erasmo of Rotterdam's De Civilitate Morum Puerilium and The Letters of Lord Chesterfield to His Son, both written in the XVIII century. Finally, this work centres on The Manual of Urbanity and Good Manners of the Venezuelan

* Dra. en Historia Universidad de Los Andes. Santiago, Chile. Correo: rsoaje@uandes.cl 
author Manuel Antonio Carreño, who expressed the ideal of life for the elite of young Spanish American nations. Thus, the final aim of this article is to contrast this book with ciceronian writing.

Keywords: Archetype, urbanity, elite persons, good manners, social behavior.

Recibido: 27.04.12. Aceptado: 29.05.14.

\section{INTRODUCCIÓN}

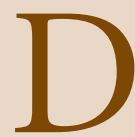

ESDE LA ANTIGÜEDAD GRIEGA y luego latina, la preocupación por los ideales de vida de las élites se vio reflejada en diversas obras literarias, épicas, líricas o bien de corte filosófico. Con el transcurrir de aquella época clásica surgió una serie de tratados morales que intentaron transmitir dichos ideales, influyendo en la educación de personajes notables de la vida pública e intelectual de sus respectivas épocas. Entre ellos destacamos el tratado De Oficiis de Marco Tulio Cicerón, que sería consultado por diversos autores medievales, modernos y también contemporáneos.

Diversos especialistas del siglo XX se han interesado por aquellos ideales clásicos de vida, propios de la cultura grecorromana, y cómo se vieron reflejados en el modo de comportamiento social ${ }^{1}$. Desde el área de la nueva historia cultural, Peter Burke (1998) realizó un estudio acerca de Los Avatares del cortesano de Baltasar Castiglione, en el cual hizo notar cómo autores romanos, de la talla de Cicerón, Ovidio y Séneca, plasmaron en sus obras la preocupación de las élites por el modo de vida que los identificaba y cómo se traducía en pautas concretas de comportamiento. Estos autores ejercieron su influencia a través de los siglos, y algunas de sus ideas fueron rescatadas en la Antigüedad Tardía, por personajes influyentes en el ámbito eclesiástico. Como antecedente de este fenómeno, Burke (1998) cita la adaptación del De Oficiis de Cicerón, que ya hiciera en el siglo IV el obispo Ambrosio, para regular el modo de conducta del clero. En la Baja Edad Media esta preocupación se vio reflejada también en las cortes; en este sentido podemos citar por ejemplo el caso de la corte castellana, para la cual Alfonso el Sabio, en sus Partidas, realiza una serie de observaciones acerca de los buenos modales que deben poseer los reyes (1807, II, V, Leyes I-VI).

\footnotetext{
${ }^{1}$ Puente Ojea (1995), en su obra Ideología e historia del fenómeno estoico en la sociedad anti$g u a$, analiza este fenómeno, enfatizando la influencia de la moral estoica en dicho proceso.
} 
Por otra parte, desde la historia de la Cortesía, Frédéric Rouvillois ha planteado la actualidad de una temática por lo demás antigua, citando al ex primer ministro británico Tony Blair, cuando en 2003 proclamaba la necesidad de declarar la guerra a la mala educación e insistía en restablecer una "cultura del respeto" (2008, p. 9).

A partir de estos antecedentes, nuestro trabajo se propone analizar la influencia del De Oficiis o Tratado de los deberes de Marco Tulio Cicerón en tres momentos claves de la Historia. Seleccionamos para este fin, dos obras modernas que han precedido a los manuales de urbanidad propios de la época contemporánea, como son: De civilitate morum puerilium de Erasmo de Rotterdam y Las cartas de Lord Chesterfield a su hijo, para abocarnos, por último, a la obra del venezolano Manuel Antonio Carreño, con el propósito de realizar un contraste entre dichas obras y el tratado ciceroniano.

\section{EL TRATADO DE ERASMO ${ }^{2}$}

Este breve manual dedicado al niño Enrique de Borgoña, hijo de Adolfo, príncipe de Veere, y redactado en Friburgo en 1530, tiene por objeto según su propio autor, en primer lugar, que el niño desde pequeño aprenda a ser piadoso, en segundo lugar que "ame las enseñanzas liberales y las aprenda bien" (Erasmo, 2006, I, p. 17); en tercer lugar, que tome conocimiento de los deberes y oficios de la vida, y por último, que "se acostumbre a la urbanidad en las maneras" (Erasmo, 2006, I, p. 17), aspecto en el cual centrará su atención.

De acuerdo con ello, la obra está estructurada atendiendo primero a las reglas de comportamiento que se relacionan con el cuerpo, su aseo, sus movimientos, su presentación exterior, etc. Ojos, boca, cejas, narices, mejillas, dientes, partes pudendas, formas de sentarse, son objeto de sugerencias e indicación. Si recurrimos a los consejos ciceronianos en este aspecto, descubriremos que, de modo similar, el romano invita al varón a vestirse dignamente (Cicerón, 1948, I, XXXVI, 1), observando "un aseo no afectado ni sobradamente rebuscado" (Cicerón, 1948, I, XXXVI, 1, p. 117), pero siempre teniendo en cuenta que "se aparte de un rústico y grosero descuido" (Cicerón, 1948, I, XXXVI, 1, p. 117).

\footnotetext{
${ }^{2}$ Para el estudio de este texto hemos utilizado la versión: Erasmo de Rotterdam (2006). De la urbanidad en las maneras de los niños. Edición bilingüe con traducción y notas de Agustín García Calvo. Edición y comentario de Julia Varela. Madrid: CIDE.
}

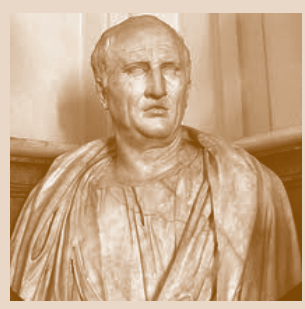

M. T. Cicerón
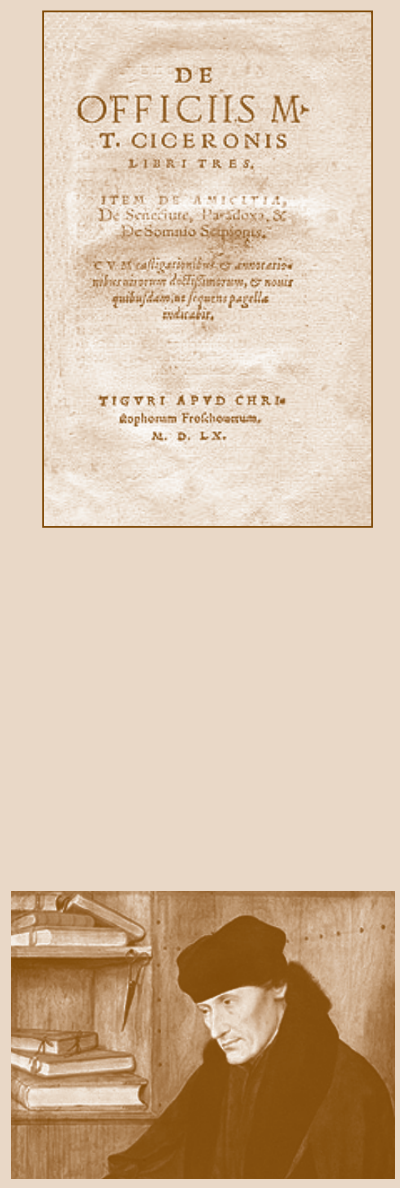

Erasmo de Rotterdam 
En segundo lugar, se atiende a la vestimenta, como expresión de la traza del espíritu (Erasmo, 2006, XII). La regla fundamental que debe regirla es la honestidad, y su utilidad se asienta en cubrir aquello que es impudor mostrar a los demás. Se recomienda evitar que dé muestras de lascivia, de frivolidad o de soberbia, que su limpieza condiga con la del cuerpo, y por último, que sea modesta. Otra vez nos recuerda las premisas del gran rétor romano, quien se refiere a la moderación que debe regir en este aspecto, insistiendo que "esta misma regla debe seguirse en el vestido en el cual como en la mayoría de las cosas lo mejor es el término medio" (Cicerón, 1948, I, XXXVI, 1, p. 117).

En tercer término, luego de ocuparse del comportamiento en el templo, la atención se focaliza en la mesa y entra también en este ámbito el tema de la conversación (Erasmo, 2006, XVII). Este aspecto es tratado nuevamente en el apartado "de los encuentros", en el cual se detallan elementos formales, desde el modo de hablar y los gestos hasta aquellos relacionados con el contenido mismo, respecto del cual destaca el ejercicio virtuoso que la conversación supone: no ensalzarse a sí mismo, no vituperar o hacer comentarios obscenos, no injuriar, etc. (Erasmo, 2006, XVIII).

En el De Oficiis el romano presta atención también a este factor clave de la vida social, atendiendo a los más mínimos detalles: que sea agradable, que no excluya a los demás, y que los temas a tratar sean reflejo de la cultura y dignidad de quienes participan en ella. Y luego da consejos también acerca del modo cómo se ha de reprender y la dignidad que se ha de guardar en las discusiones. El acento está puesto en la intención de agradar a los demás, a través de una conversación elevada y a la vez entretenida (Cicerón, 1948, XXXVII-ss).

Finaliza el tratado de Erasmo con indicaciones acerca de los juegos apropiados para los niños de bien, y sus reglas; y así como el día acaba en el dormitorio, el apartado final se dedica también a ello (2006, XIX).

El epílogo, por su parte, refuerza el objetivo inicial de la obra, dedicada, a través de Enrique, a todos los niños del mundo, para que se granjeen el ánimo de sus camaradas y para que les hagan estimables los estudios liberales y los referidos a las buenas maneras (Erasmo, 2006, XX).

Norbert Elias se ha ocupado expresamente de este texto en su intento de mostrar cómo los usos y costumbres que se aceptan como naturales, en realidad, son el resultado de un largo aprendizaje. Elias toma esta obra como 
expresión de ruptura respecto a la tradición medieval, inaugurando la concepción más moderna del buen vivir (Elias, 1997), puesta de manifiesto en parte a través de la sustitución de términos fundamentales. En efecto, Erasmo reemplaza el término civitas por civilitas, lo cual, según Elias, le servirá a la sociedad europea moderna para definirse a sí misma como civilizada; en este sentido, las buenas maneras constituyen los signos de la civilidad de las nuevas élites, quienes serán las encargadas de difundir esos buenos modales. Cabe destacar que es Erasmo quien incorpora este nuevo concepto de civilitas, no referido ya necesariamente al orden y gobierno de una ciudad, sino más bien al modo como todo hombre educado debe comportarse en sociedad (Elias, 1997). Esto responde quizás al avance de un individualismo que se va imponiendo a medida que se relaja el orden político y social medieval (Cataldo, 2004).

El antecedente de este tratado debemos buscarlo en obras de cortesía bajomedieval, tales como la Glosa castellana al Regimiento de Príncipes, El caballero Cifar, el Llibre de Cortesía, Las flores de filosofía y otras (Varela, 2006). Las mismas aparecen en las cortes a medida que se gestan y consolidan importantes cambios económicos y sociales, precisamente cuando el saber cortesano, en opinión de José Antonio Maravall, se traduce en una concepción peculiar de la vida, que afecta el comportamiento y las relaciones humanas. Se trata, en definitiva, de un saber moral destinado a regular la vida de sociedad, atesorado especialmente por el alto linaje, el cual se identifica como el depositario de la virtud (Maravall, 1967, cit. en Varela, 2006).

Por último, cabe destacar que, al igual que Cicerón, Erasmo hace hincapié en la importancia del decoro exterior del cuerpo, como expresión de un alma bien compuesta. En primer término, para ganarse la benevolencia de los demás, pero también para demostrar la compostura íntegra en alma, cuerpo, acciones y vestimenta, lo cual conviene a todos, pero en especial a los niños, y sobre todo a los de noble cuna (Erasmo, 2006, I). Es interesante destacar que, de modo similar a como lo hace el rétor romano, el autor declara que la nobleza verdadera se asienta en aquellos que cultivan sus almas con los estudios liberales (Erasmo, 2006, I) y luego añade, más bien que en aquellos que pintan sus escudos con leones, águilas, toros o leopardos $(2006, \mathrm{I})$. 


\section{LAS CARTAS DE LORD CHESTERFIELD SOBRE EL ARTE DE AGRADAR}

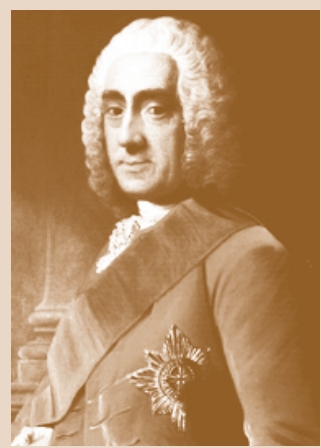

L. Chesterfield
Lord Chesterfield, destacado diplomático y escritor de comienzos del siglo XVIII, nacido en 1694 y educado en Londres por tutores especiales, ha sido reconocido como un gran aficionado al estudio de los clásicos. En las cartas que escribió a su hijo, esta afición se refleja con toda nitidez, pues constituyen verdaderas lecciones de diversas materias tales como historia, literatura y moral clásicas, además de otros variados temas de interés. Entre ellos, destaca la preocupación por transmitir tanto a Felipe, su hijo, como luego a su ahijado Stanhope, heredero de su fortuna, consejos acerca del modo de comportarse en sociedad para triunfar en el mundo europeo dieciochesco. Dice al primero:

Debes saber, que así como la ciencia, el honor y la virtud son cosas absolutamente necesarias para que adquieras el aprecio y admiración de las gentes, de la misma manera, la urbanidad y el buen porte, lo son para que halles buena acogida y seas grato en la conversación y en la vida ordinaria... Además de la cortesía que es absolutamente necesaria, la perfección de la buena crianza consiste en ser urbano con desembarazo y aire de caballero (Lord Chesterfield, 1852, p. 34).

A lo largo de los años, en sus cartas va desgranando estas reglas de urbanidad inglesas que influyeron ampliamente en España (Varela, 2006) y que se desprenden de lo que él mismo menciona como "grande y fundamental principio de moralidad" (Lord Chesterfield, 1852, p. 336): "lo que a ti te agradare agradará probablemente a los demás" (Lord Chesterfield, 1852, p. 49). A este se añade como corolario que "un hombre que no agrada generalmente es un ser nulo e insignificante" (Lord Chesterfield, 1852, p. 345).

Incita también a su hijo al conocimiento de los hombres pues "es un conocimiento muy útil para toda clase de personas, pero para ti que te destinas a una vida pública y activa es de lo más necesario" (Lord Chesterfield, 1852, p. 162).

Se preocupa además porque el joven viva de forma ordenada y con moderación:

\footnotetext{
${ }^{3}$ Para este estudio hemos utilizado la edición: Lord Chesterfield (1852) Cartas completas. Traducción española de Luis Maneiro, Havre, Imprenta de Alfonso Lemale.
} 
¿Podré esperar que fijes una hora cada semana para arreglar tus negocios y tenerlos bajo aquel método y orden de un hombre prudente?... ¿Podré persuadirme de que confinarás tus placeres, sean los que fueren, dentro del límite de la buena compañía y de la decencia? (Lord Chesterfield, 1852, p. 176).

Las cartas a su ahijado, pariente lejano suyo, escritas probablemente entre 1765 y 1766, tienen como fin expreso y principal instruirlo "sobre el deber, la utilidad y los medios de agradar..." (Lord Chesterfield, 1852, p. 335). Considera que el deseo de que se nos agrade es universal, por lo cual también debería serlo el de agradar a los demás. En este sentido, entra en "aquel grande y fundamental principio de moralidad de obrar con los otros del mismo modo que desearíamos que ellos obrasen a nuestro respecto" (Lord Chesterfield, 1852, p. 336). Si bien reconoce que hay deberes morales superiores considera que ninguno es más amable que este, al que desea colocar "a la cabeza de lo que Cicerón llama leniores virtutes" (Lord Chesterfield, 1852, p. 336). Llama la atención que el autor hace referencia al mismísimo Cicerón acusando así la influencia del romano, situación que se confirma cuando hace alusión a la "decoración"4 (Lord Chesterfield, 1852, p. 336), como sinónimo de buena crianza y lustre de la urbanidad, la cual se adquiere gracias a la atención que se presta a la buena compañía, definida con sumo detalle, y al hábito de frecuentarla (Lord Chesterfield, 1852).

Una de las reglas claves en este arte es la de dedicar atenciones a los demás, teniendo en cuenta siempre las circunstancias de tiempo, lugar y personas (Lord Chesterfield, 1852). Otra es tener dominio de sí mismo para subyugar los propios humores. Entra a jugar aquí el principio del dominio de las pasiones, tan caro a Cicerón que implica el ejercicio de la templanza, tal como lo aconseja el rétor al tratar de la última parte de la honestidad, referida a esta virtud (Cicerón, 1948, I, XXVII, 1).

Además, el autor inglés dirige un apartado especial a las gracias, tanto las del espíritu, que comunican de manera seductora los pensamientos y expresiones, como las del cuerpo, que influyen en los movimientos, posturas y destrezas (Lord Chesterfield, 1852).

El ingenio ocupa también su atención y apunta directamente a la agudeza y al modo de agradar a través de la conversación. "Un hombre prudente vive por lo menos dentro de los límites de su ingenio como dentro de los de

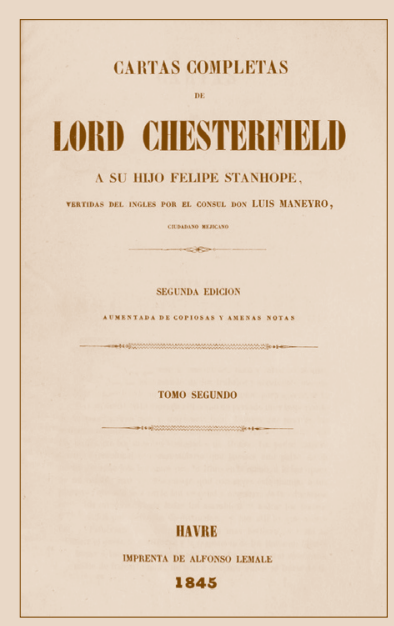


su renta" (Lord Chesterfield, 1852, p. 340), advierte a su ahijado. Aconseja además en este ámbito del trato verbal con los semejantes, evitar hablar de sí mismo, lo cual es signo de vanidad, tanto para alabarse como para condenarse; pues la vanidad es odiosa y repugnante. La máxima en este caso es: “... deja que tu carácter hable por ti” (Lord Chesterfield, 1852, p. 342).

Ser generoso y benévolo por naturaleza y no de forma afectada es también conveniente en el arte de agradar; buscar el lado favorable de la cuestión, evitar las insinuaciones desagradables y los rumores. "Es imposible ser amable sin la realidad y las apariencias de la benevolencia" (Lord Chesterfield, 1852, p. 343). Inmediatamente después, llama a observar detenidamente los gustos, humores, singularidades, aficiones y antipatías de los demás, ya sea para poder satisfacerlas o evitarlas, según el caso y la ocasión.

Los temas de la conversación también son objeto de preocupación: religión, política, noticias, son indicados como ejemplos de aquellos. Se pregunta en cada caso qué temática elegir y qué resguardos colocar según las circunstancias (Lord Chesterfield, 1852).

En definitiva, la discreción señala el "a propósito" de todas las cosas que se dicen o hacen, y debe traducirse en manejar la familiaridad porque: "la mucha familiaridad, según el dicho muy antiguo, engendra desprecio, y a veces querellas...y muy poca indica una formalidad insociable" (Lord Chesterfield, 1852, p. 344). En los párrafos finales, el autor reflexiona sobre la naturaleza humana, la cual puede ser cultivada y mejorada, tanto en el cuerpo como en el alma, y en realidad, todo su esfuerzo se aplica a este último precepto. En ese proceso de cultivo aconseja también no forzar a la naturaleza ni aparentar ser lo que no se es, pues esto es señal de torpeza. Y como no podía ser de otro modo, aparece aquí el decorum, como medida de discreción para la acción: "La expresión de Cicerón decorum es propiamente la cosa y yo no sé por qué razón no se adoptaría y naturalizaría en el idioma inglés" (Lord Chesterfield, 1852, p. 344), nos dice con pesar.

\section{CARREÑO Y LAS BUENAS MANERAS ${ }^{5}$}

Pasado el furor de la Revolución Francesa, que provocó una reacción de anticortesía en la Europa de fines del siglo XVIII, las buenas maneras reaparecen a partir de 1800, dando lugar a lo que Frédéric Rouvillois ha llamado la

\footnotetext{
${ }^{5}$ Hemos utilizado la edición: Carreño, Manuel Antonio (1863) Compendio del manual de urbanidad y buenas maneras. arreglada por él mismo. Valparaíso. Imprenta y librería del Mercurio.
} 
Edad de Oro de la cortesía burguesa. "El gran señor de antes del '89 no necesitaba ser cortés para sentirse superior; el pequeño burgués del siglo XIX lo necesitaba imperiosamente" (2008, p. 59). Es así como surgen los manuales de urbanidad que buscan codificar un determinado modo de vida para que sea conocido, aplicado y difundido. En el siglo XIX el progreso de la clase media y su movilidad social hacen indispensable esta codificación, que se da tanto en Europa como del otro lado del Atlántico (Rouvillois, 2008). Sin embargo, dicha sistematización alterará sustancialmente las características de la urbanidad, y la soltura de la cortesía prerrevolucionaria dará lugar a "un rigorismo... importado de Inglaterra que marcará profundamente los códigos del savoir-vivre a partir de 1830" (Rouvillois, p. 59), influyendo sensiblemente en las modas y maneras que ahora se teñirán a la inglesa. El burgués conocerá los detalles de la cortesía y, llevándolos a la práctica, alcanzará a las élites y se distinguirá de las capas sociales inferiores a él (Rouvillois, 2008).

La situación descrita se trasladará a América, donde se produciría un fenómeno similar. En este sentido, observa Lander, el Manual de Carreño representa, al igual que otros de la misma especie y época, una respuesta clara a la necesidad de asimilar las élites criollas a los cánones de la sociedad europea civilizada (Lander, 2002). De modo similar a los anteriores, aunque con mayor sistematización, dicho manual recoge diversas reglas y normas de conducta, cuyo cumplimiento considera necesario para hacer más grata y fructífera la convivencia social ${ }^{6}$.

Manuel Antonio Carreño, diplomático y político de origen venezolano, vivió entre 1812 y 1874, un periodo clave para las jóvenes naciones hispanoamericanas como la suya. Su obra fue publicada por entregas en 1853, y el título de su primera versión fue Manual de urbanidad y buenas maneras, para uso de la juventud de ambos sexos, en el cual se encuentran las principales reglas de civilidad y etiqueta que deben observarse en diversas situaciones sociales, precedido de un breve tratado sobre los deberes morales del hombre. Fue tal su difusión y trascendencia, que dos años después el Congreso Nacional venezolano recomendó su uso (Malaver, 2005).

El tratado introductorio de dicho manual, que se refiere a los deberes morales del hombre, toma como modelo la concepción ciceroniana relacionada con la importancia de dos elementos claves a través de los cuales se deben ejercer las obligaciones propias de la vida: la patria y el hogar, a la cabeza de las cuales Carreño coloca a Dios.

\footnotetext{
${ }^{6}$ Para un análisis más detallado del siguiente apartado vid. Soaje (2012).
}

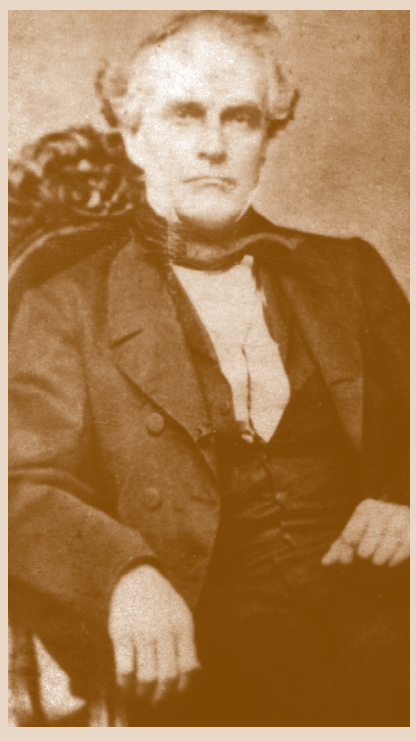

M. A. Carreño 
Conviene en este punto recordar el concepto de deber que Cicerón presenta en su tratado De Oficiis, haciéndolo derivar de lo honesto, que a su vez:

... o consiste en el conocimiento de la verdad y en la viveza del ingenio; o en fomentar la sociedad de los hombres dando a cada uno lo suyo...; o en la grandeza y fortaleza de un alma excelsa e inquebrantable; o en el orden y medida en cuanto se dice y se hace, en lo que estriban la moderación y la templanza. Aun cuando estas cuatro cosas están ligadas entre sí e implicadas unas en otras, sin embargo de cada una nace una determinada especie de deberes (Cicerón 1948, I, V, p. 40-ss).

Carreño por su parte, no se detiene en una disquisición filosófica semejante y parece dar por hecho que el lector sabe las implicancias fundamentales del término. Del mismo modo, como lo hace Cicerón, el tratado buscará incentivar a las jóvenes generaciones, partiendo de ciertas instancias primordiales respecto de las cuales se debe ejercer la virtud. De este modo, el apartado introductorio acerca de los deberes morales del hombre tiene en cuenta los consejos de Cicerón en cuanto a que las obligaciones que deben merecer mayor atención son aquellas que se refieren a la patria y a los propios padres, y luego a los hijos y a la casa (1948, I, XVII, 1). Pero a ellas el venezolano añade los deberes para con Dios que constituyen el fundamento de los demás, pues en ellos dice el autor:

... se encuentran refundidos todos los deberes sociales y prescripciones de la moral; asi es que el hombre verdaderamente relijioso es siempre el modelo de todas las virtudes, el padre mas amoroso, el hijo mas obediente, el esposo mas fiel, el ciudadano mas útil a su patria (Carreño, 1863, I, X, p. 8).

Con respecto, a los padres, ellos son los responsables de la formación y educación, tanto moral como intelectual, de sus hijos (Carreño, 1863, II, I, XIII). Asimismo, los maestros son delegados suyos en las tareas de formar el corazón en el honor y en la virtud, e ilustrar el espíritu (Carreño, 1863, II, I, XIX).

Sugiere además:

... gozarnos en el cumplimiento de los deberes que nos han impuesto para con nuestros padres las leyes divinas y la misma naturaleza. Amarlos, honrarlos, respetarlos y obedecerlos, he aquí estos grandes y sagrados deberes, cuyo sentimiento se desarrolla en nosotros desde que tenemos uso de razón (Carreño, 1863, II, I, XIII, pp. 15-16). 
Aparece aquí el concepto de naturaleza, tan caro a Cicerón, la cual engendra, según dice el rétor, un amor especial para con los hijos, obligando a desear que haya unión y sociedad entre los hombres en general, y en especial hacia aquellos que el ser humano está obligado a proteger (Cicerón, 1948, I, IV, II).

Al dedicarse a los deberes para con la patria, Carreño la define primero como:

... toda aquella estensión de territorio, gobernado por las mismas leyes que rijen en el lugar que hemos nacido, donde formamos con nuestros conciudadanos una gran sociedad de intereses y sentimientos nacionales (1863, II, II, I, pp. 18-ss),

en la cual:

... las ciudades, los pueblos, los edificios, los campos cultivados, y todos los demás signos y monumentos de la vida social nos representan a nuestros antepasados y sus esfuerzos jenerosos por el bienestar y la dicha de su posteridad (1863, II, II, III, p. 19).

Y luego de varias consideraciones acerca de su importancia fundamental, afirma que "la vida misma le pertenece" en caso de que las circunstancias lo requieran" (1863, II, II, III, p. 19).

Cicerón por su parte dedica un apartado de su obra a mostrar igualmente la grandeza de la patria y las obligaciones que el ciudadano tiene para con ella. En este sentido nos dice que:

... ninguna unión es más fuerte, más querida que la que tiene cada uno de nosotros con la república. Queridos son nuestros padres, nuestros hijos, nuestros parientes nuestros amigos, pero a todos los amores de todos los ha abarcado una sola patria por la cual ¿Qué hombre vacilará en sufrir la muerte si ha de servirle a ella? (1948, I, XVII, 5, p. 67).

Junto con los deberes, el concepto de urbanidad ocupa un lugar central en la obra de Carreño. Definida como un "conjunto de reglas que deben observarse para comunicar a nuestras acciones y palabras dignidad, decoro y elegancia y para manifestar benevolencia, atencion y respeto a los demás" (1863, II, I, I, p.32), es considerada, por tanto, como emanación de los deberes morales del hombre, antes mencionados, según lo cual:
COMPENDI0

MANUAL DE URBANIDAD

Y BUENAS MANERAS

manuel antonto CARTENo.

ARREGLAno POR hit. MISs

PARA EL USO DE LAS ESCUET.AS DE AMBOS SEXOS

$\cdots$

VALPARAISO,

TMPRENTA Y LIBRERTA DEL MERCURIO de Santos Tornero.

1863. 
sus prescripciones tienden todas a la conservación del órden y de la buena armonia que deben reinar entre los hombres, y a estrechar los lazos que los unen por medio de la impresiones agradables que produzcan los unos sobre los otros (1863, II, I, II, p. 32).

Cabe advertir, sin embargo, que en este punto, el tratado adquiere una evolución propia de los ideales de vida decimonónicos, representativos de una sociedad civilizada, cuyos miembros aspiran a la estimación y al respeto, como medio para alcanzar "el éxito que ofrece el futuro moderno" (Lander, 2002, p. 84).

El tema ha sido estudiado desde una perspectiva social por sociólogos de la talla de Durkheim y Norbert Elias, y, más recientemente, Michael Foucault entre otros (Lander, 2002; Foucault, 2002). Los argumentos de estos autores giran en torno a la imposición de normas por una clase dominante, como símbolo de identidad, o bien como medio de representación de un estilo de vida, a través del cual el grupo en cuestión se diferencia de los demás, sea la aristocracia cortesana de los siglos XVI y XVII, o bien la burguesía en ascenso en el XVIII y el XIX, a la cual se sumarían las élites criollas de la América hispana. El debate se traslada entonces al plano ideológico y apunta a probar cómo lo supuestamente natural en el ámbito de las costumbres humanas es una imposición, aprendida lentamente, por voluntad de un sector social dominante, planteándose así una dicotomía entre cultura y naturaleza, como dos entidades opuestas y contradictorias ${ }^{7}$. Si tenemos en cuenta, sin embargo, el pensamiento clásico al cual adhirió Cicerón, a quien hemos tomado como antecedente de Carreño, deberíamos concebir a la naturaleza de un modo teleológico, el cual, como observa el filósofo Jorge Peña,

remite de suyo al ámbito de la cultura, de suerte que puede afirmarse que el hombre es por naturaleza un ser social y cultural. Para los griegos la naturaleza es tendencia hacia una perfección y el hombre, precisamente por su racionalidad que le permite conocer esa teleología inmanente, es capaz de llevar a la naturaleza a su plenitud (Peña Vial, 2000, p. 52).

\footnotetext{
${ }^{7}$ En su obra Vigilar y castigar, Foucault incorpora un análisis de la imposición de la disciplina al cuerpo con el objeto de hacerlo dócil, se trata de "trabajarlo en sus partes, de ejercer sobre él una coerción débil, de asegurar presas al nivel mismo de la mecánica: movimientos, gestos, actitudes, rapidez; poder infinitesimal sobre el cuerpo activo. ... A estos métodos que permiten el control minucioso de las operaciones del cuerpo, que garantizan la sujeción constante de sus fuerzas, y les imponen una relación de docilidad-utilidad, es a lo que se puede llamar disciplinas" (Foucault, 2002, pp. 140-141).
} 
Fue el pensamiento de la Ilustración el que registró una ruptura en aquello que el pensamiento clásico ve como una continuidad, al cambiar el concepto de naturaleza tomándolo como principio del movimiento humano y no como fin; en este sentido, dirá el filósofo, se identifica "lo empíricamente dado al principio, como distinto de lo adquirido" (Peña Vial, 2000, p. 36).

La obra de Carreño se detiene además en la consideración de las buenas maneras, aquello que Cicerón definiría como Decorum ${ }^{8}$ :

Por medio de un atento estudio de las reglas de urbanidad y por el contacto con personas cultas llegamos a adquirir lo que especialmente se llama buenas maneras o buenos modales, lo cual no es otra cosa que la decencia, moderación y oportunidad en nuestras acciones y palabras, y aquella delicadeza y gallardía que aparecen en todos nuestros movimientos exteriores, revelando la suavidad de las costumbres y la cultura del entendimiento (1863, II, I, IV, p. 33).

Según observa Camarero en su estudio titulado "La teoría eticoestética del decoro en la antigüedad", los términos: prepon, decorum y afines hacen referencia a aquello que es debido al hombre, es decir a su dignidad superior a todo lo creado, y son indicadores de lo bello en la época clásica (Camarero, 2000). El término deriva del griego, en cuyo idioma To prepon significa lo conveniente. El verbo prepein podría traducirse por distinguirse, hacerse notar. Está referido principalmente a la persona, en su aspecto exterior, vestimenta, arreglo, grata apariencia, prestancia física, o bien demuestra excelencia por su condición humana. Se usa en el sentido más preciso de ser adecuado, de buen gusto, elegante, de allí que se aplica también a la acción del hombre (Camarero, 2000). Debe aclararse que no se refiere a conveniencia en el sentido de utilidad, deber moral, ventaja o necesidad, sino a lo que conviene al hombre según su naturaleza (Puente Ojea, 1995).

$\mathrm{Al}$ aplicar este concepto a toda obra humana, comienza a identificarse el prepon con la belleza, definida como el esplendor de lo conveniente. Se da así una conjunción entre lo bello y lo bueno, lo que se traduce en una ética social e individual que obliga al hombre a comportarse de un modo agradable en relación con los demás (Camarero, 2000).

El decoro, en opinión de Cicerón, es en todo caso inseparable de la honestidad, como lo es la salud de la gracia y hermosura del cuerpo, “... pues

\footnotetext{
${ }^{8}$ Para un análisis más detallado de este aspecto, vid. Soaje (2010).
} 
lo que es decoroso es honesto y asimismo, lo que es honesto es decoroso" (Cicerón, 1948, I, XXVII, 1, p. 91).

Recordemos que lo honesto, en el lenguaje de los filósofos clásicos, es el sumo bien o bien en sí mismo, independientemente de la utilidad que pueda prestar (Cicerón, 1948, I, II, 3). Así todo lo que es bueno por sí mismo es a la vez decoroso (Cicerón, 1948, I, XXVII, II).

¿En qué consiste el decoro entonces? Es, en realidad, el ornato de la vida, por tanto no se da en una sola virtud sino más bien se presenta en todas ellas "como un cierto aire de nobleza y dignidad" (Gómez Robledo, 1948, p. 21). Lo cual se puede percibir en la conducta del hombre por el orden, igualdad y arreglo de sus acciones y palabras, con todos los que lo rodean sin atender a que sea noble, sabio o vulgar (Cicerón, 1948, I, XXVIII, 2). En definitiva: aquel que guarda compostura en todas las circunstancias y lugares, demuestra comportarse con decoro y así demuestra la excelencia de la naturaleza humana, adaptándola a su naturaleza individual, y realzando de este modo la gracia de la propia persona por su cultura y dignidad (Cicerón, 1948, I, XXVII, 4, p. 93).

En definitiva, concluye el rétor:

Así como la belleza del cuerpo atrae a los ojos por la proporcionada disposición de sus miembros, y deleita por lo mismo que todas las partes armonizan entre sí con cierta gracia, así también lo decoroso que esplende en la vida logra la aprobación de aquellos con quienes se vive, por el orden, la constancia y la moderación en todo cuanto se dice o hace (Cicerón, 1948, I, XXVII, 2, p. 95).

Si consideramos ahora nuevamente a Carreño descubriremos que, por una parte, acusa recibo del pensamiento ciceroniano rescatado a lo largo de los siglos, pero por otra parte, como hijo de su tiempo, se ve imbuido de los ideales propios de la civilización, tal como fueron acuñados por la sociedad europea del siglo XVIII, y cuyo antecedente más preciso en la época moderna es el mencionado De civilitate morum puerilium de Erasmo, que enlaza directamente con dichos tratados de cortesía y con aquellos otros destinados al arte de amar o agradar, los cuales a su vez tuvieron su antecedente en los tiempos clásicos?.

En este sentido, afirma Carreño: dos.

${ }^{9}$ Recordemos al respecto El arte de amar de Ovidio, como uno de los ejemplos más conoci- 
La civilidad presta encantos a la virtud misma; y haciéndola agradable y comunicativa, le conquista partidarios e imitadores en bien de la moral y de las buenas costumbres (1863, II, I, XIV, p. 37).

Esta última reflexión nos introduce en una concepción definida en la modernidad como moral de las bellas apariencias, la cual vincula lo ético y lo estético aparentemente en pos de un fin utilitario (Cataldo, 2004; Sherman, 2005). En este sentido, cabe preguntarse hasta qué punto dichos tratados de urbanidad impulsan a la virtud, o a la hipocresía. El problema ha sido estudiado por filósofos modernos como Kant y Schiller, pero tiene sus antecedentes en la antigüedad clásica, desde los tiempos de Platón, cuando éste reflexionaba acerca de la esencia de la belleza y su relación con la verdad (Cataldo, 2004). Con Kant el problema se traslada a la vinculación entre belleza y ética, y en este sentido, el filósofo alemán se plantea precisamente si la cortesía es una mera apariencia. Cabe aclarar que, según observa Cataldo, la expresión apariencia posee una doble connotación; por una parte, supone ocultar o disimular algo, pero por otra, lo que aparece a la vez revela o muestra algo, con lo cual el término adquiere un sentido estético (Cataldo, 2004). En la Crítica del juicio, Kant aborda esta problemática para afirmar finalmente que hacer de alguien una persona educada no equivale a hacerlo moralmente bueno, pero en cambio lo predispone hacia esta condición (1991, cit. en Cataldo, 2004).

Por último, cabe destacar que el decoro, rescatado por Carreño, constituye el rasgo esencial del ideal de Humanitas definido por Cicerón (Lord Chesterfield, 1852), ideal que se difundió en el Renacimiento, con obras tales como el mencionado tratado de Erasmo o bien el de El Cortesano de Castiglione cuyo aspecto central, según observa Hayes (1939), fue precisamente el cultivo de todos los aspectos de la naturaleza humana.

\section{CONCLUSIÓN}

Según hemos podido percibir a lo largo de nuestro estudio, el manual de Carreño es el heredero de una larga tradición de textos que intentaron educar a las generaciones de su tiempo en normas básicas de conducta, incorporando, no obstante, los nuevos aportes y conceptos que fueron generando las distintas épocas.

Constatamos así el hecho que, mientras Cicerón proponía en su tiempo el arquetipo de la Humanitas, como ideal estético y aristocrático de vida, en orden a alcanzar la virtud, el manual de Carreño apuntaría a un objetivo 
similar que buscaba formar al ciudadano modelo de las jóvenes naciones hispanoamericanas. A ello añadiría el venezolano la enseñanza cristiana respecto de las virtudes, que se había transformado en parte de la tradición de un estilo de vida propio de las élites, el cual recorrería la Historia desde la baja Edad media hasta los tiempos modernos y contemporáneos, según hemos podido apreciarlo a través de las obras de Erasmo y de Lord Chesterfield.

Las buenas maneras se transformarían así en bellas apariencias que pueden impulsar al hombre a la virtud, tal como se lo proponía Cicerón al pintar un bello cuadro a su hijo, luego de presentarle el sumo bien y las obligaciones que se derivan del mismo:

Ya puedes contemplar, hijo mío Marco, la hermosura misma y como la faz de la honestidad, la que si lograra verse con los ojos, despertaría, como dice Platón, un maravilloso amor por ella (Cicerón, 1948, I, V, 1, p. 39).

\section{REFERENCIAS}

Alfonso el Sabio (1807). Las siete partidas. Madrid: Imprenta Real. Burke, P. (1998). Los avatares de El cortesano. Barcelona: Gedisa.

Camarero, A. (2000). La teoría eticoestética del decoro en la antigüedad. Bahía Blanca: Ediuns.

Carreño, M. A. (1863). Compendio del manual de urbanidad y buenas maneras. Valparaíso: Imprenta y Librería del Mercurio.

Cataldo Sanguinetti, G. (2004). "Las buenas maneras o la moral de las apariencias". Revista de Humanidades, 10: 7-19.

Cicerón, M. T. (1948). De los deberes. Introducción de Antonio Gómez Robledo. Versión española y notas de Baldomero Estrada Morán. México: UNAM.

Elias, N. (1997). El proceso de la civilización. Investigaciones sociogenéticas y sicogenéticas. Colombia: Fondo de Cultura Económica.

Erasmo de Rotterdam (2006). De la urbanidad en las maneras de los niños. Edición bilingüe con traducción y notas de Agustín García Calvo. Edición y comentario de Julia Varela. Madrid: CIDE.

Foucault, M. (2002). Vigilar y castigar. Buenos Aires: Siglo XXI.

Gómez Robledo, A. (1948). “Introducción”, en: Cicerón, M. T., De los deberes. México: UNAM.

Hayes, G. (1939). “Cicero's Humanism Today”. The classical Journal, 34(5): 283290.

Lander, M. F. (2002). "El Manual de urbanidad y buenas maneras, de Manuel Antonio Carreño: Reglas para la reconstrucción del ciudadano ideal". Arizona Journal of Hispanic Cultural Studies, 6: 83-96. 
Lord Chesterfield (1852). Cartas completas. Trad. Española de Luis Maneiro. Havre: Imprenta de Alfonso Lemale.

Malaver, I. (2005). "Estudio socioprogramático del Manual de urbanidad y buenas maneras de Manuel Antonio Carreño”. Boletín de Lingüística, 24: 55-75.

Peña Vial, J. (2000). "Diversas acepciones de la naturaleza en su relación con la cultura”. Anuario de Filosofía Jurídica y Social, 18, 25-57 (Sociedad Chilena de Filosofía Jurídica y Social).

Puente Ojea, G. (1995). Ideología e historia del fenómeno estoico en la sociedad antigua. Madrid: Siglo XXI.

Rouvillois, F. (2008). Historia de la cortesía de 1789 a nuestros días. Buenos Aires: Claridad.

Sherman, N. (2005). "Of manners and morals". British Journal of Educational Studies, 53(3): 272-289.

Soaje, R. (2010). "Vestigios romanos en reglas monásticas de la Hispania tardoantigua”, en: XIV Semanas de Estudios Romanos. UCV, Valparaíso, 6-8 septiembre. (Inédito).

. (2012). "La influencia del De Oficiis de Cicerón en la historia de la urbanidad: El caso del Manual de Carreño”. Boletín de la Academia Chilena de la Historia, LXXVIII, No 121 (enero-junio), 201-212.

Varela, J. (2006). Edición y comentario, en: Erasmo de Rotterdam, De la urbanidad en las maneras de los niños. Madrid: CIDE. 